\title{
RECONCILING THE LITHOLOGIC AND PALEOBOTANIC RECORDS OF CLIMATIC CHANGE DURING THE PENNSYLVANIAN
}

GYLLENHAAL*, Eric D., Paleogeographic Atlas Project, University of Chicago, 5734 S. Ellis Ave., Chicago, IL 60637, U.S.A., and Field Museum of Natural History, Roosevelt Rd. at Lake Shore Dr., Chicago, IL 60605, U.S.A.

Both lithologic and paleobotanic data have been used to construct climatic curves for the Pennsylvanian of the Appalachian Basin (Figure 1). The strengths and weaknesses of each type of evidence must be considered when reconciling these data into a composite curve. (1) The calibrated lithologic curve is based ultimately on the geographic ranges of sediments and soils relative to modern precipitation. Although it provides quantitative estimates of precipitation, the calibrated curve cannot detect minor fluctuations in climate, and time-averaging of range data can lead to an over-estimate of the rate of climatic change. (2) The geochemical model, although uncalibrated, uses essentially the same data as the calibrated curve. It avoids some of the problems of time-averaging by incorporating rough estimates of abundance. Although the long-term curve portrays a uniform climate during the earlier Pennsylvanian, lithologic data may be insensitive to climatic fluctuations in extremely wet climates. (3) The abundance of arborescent lycopods in coal may be a useful climatic indicator through much of the Pennsylvanian, but its usefulness in the Mississippian (before the evolution of non-lycopod swamp trees) and the latest Pennsylvanian (after a major extinction of arborescent lycopods) must be questioned. (4) The abundance of coal resources (as with any other climatic indicator) depends on many factors other than climate. The lack of congruence between the coal abundance curve and the other curves emphasizes the importance of including non-climatic factors in any model that predicts coal resources based on paleoclimate.

The composite curve takes its overall shape from the geochemical model, quantifies it using the calibrated curve, and details climatic trends in the wet lower Pennsylvanian based on lycopod abundance data. The major weakness of the composite curve is that it ignores potential variations in seasonality of precipitation.

Calibrated

Lithologic Data

(Gyllenhaal, 1990)
Geochemical Model

(Cecil, 1990)

Long-term Short-term Abundance trend
Coal

Abundance Composite

(Phillips et (Long-Term)

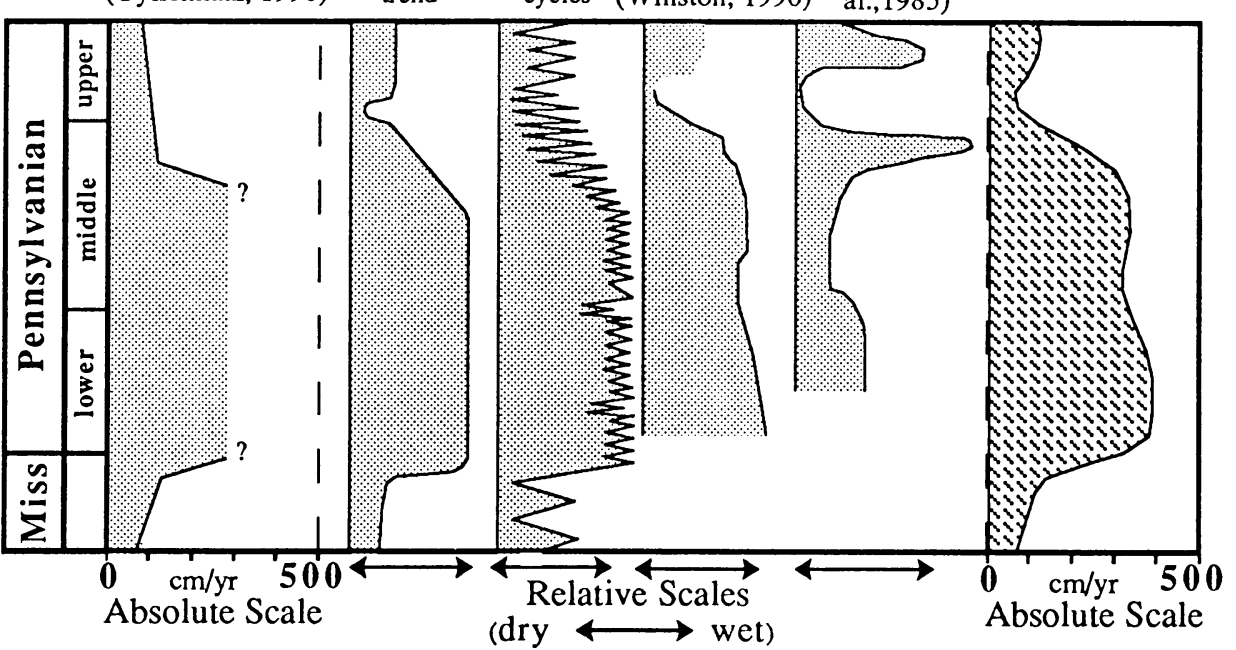

Figure 1. Climatic curves for the Pennsylvanian of the Appalachian Basin. 